\title{
Investigation of Salmonella Enteritidis Outbreak Associated with Truffle Oil — District of Columbia, 2015
}

\begin{abstract}
S. Janet Kuramoto-Crawford, $\mathrm{PhD}^{1,2}$; Sasha McGee, $\mathrm{PhD}^{2}$; Keith Li, $\mathrm{MPH}^{2}$; Andrew K. Hennenfent, DVM ${ }^{2,3}$; Kossia Dassie, MPH ${ }^{2}$; Jhetari T. Carney, $\mathrm{MPH}^{2,4}$; Arian Gibson${ }^{5}$; Ivory Cooper ${ }^{5}$; Morris Blaylock, PhD ${ }^{6}$; Reginald Blackwell ${ }^{6}$; Angela Fields, MPH${ }^{7}$; John Davies-Cole, PhD ${ }^{2}$
\end{abstract}

On September 8, 2015, the District of Columbia Department of Health (DCDOH) received a call from a person who reported experiencing gastrointestinal illness after eating at a District of Columbia (DC) restaurant with multiple locations throughout the United States (restaurant A). Later the same day, a local emergency department notified DCDOH to report four persons with gastrointestinal illness, all of whom had eaten at restaurant A during August 30-September 5. Two patients had laboratory-confirmed Salmonella group D by stool culture. On the evening of September 9, a local newspaper article highlighted a possible outbreak associated with restaurant $\mathrm{A}$. Investigation of the outbreak by $\mathrm{DCDOH}$ identified 159 patrons who were residents of 11 states and DC with gastrointestinal illness after eating at restaurant A during July 1-September 10. A case-control study was conducted, which suggested truffle oil-containing food items as a possible source of Salmonella enterica serotype Enteritidis infection. Although several violations were noted during the restaurant inspections, the environmental, laboratory, and traceback investigations did not confirm the contamination source. Because of concern about the outbreak, the restaurant's license was suspended during September 10-15. The collaboration and cooperation of the public, media, health care providers, and local, state, and federal public health officials facilitated recognition of this outbreak involving a pathogen commonly implicated in foodborne illness.

\section{Epidemiologic Investigation}

To identify food items associated with gastrointestinal illness, DCDOH initiated a case-control study; a case was defined as the occurrence of gastrointestinal illness in a person beginning $\leq 7$ days after eating at restaurant A during July 1-September 10, 2015. Cases were categorized as confirmed (Salmonella group D isolated from a clinical specimen by culture) or probable (linked epidemiologically, but without laboratory confirmation of Salmonella). Case-patients were identified on the basis of laboratory reports confirming Salmonella, self-report (i.e., contacted DCDOH directly), notifications from health care providers, and referrals from other restaurant patrons. Control subjects ate at restaurant A during July 1-September 10, 2015, but did not report gastrointestinal illness. Control subjects were identified through case-patients or self-reported to DCDOH. Case-patients and control subjects were interviewed using the $\mathrm{DCDOH}$ foodborne investigation questionnaire and were asked to review restaurant A's online menu and list all food items ordered, shared, or tasted. Sociodemographic and clinical information (e.g., symptoms, doctor visits) was also collected.

During September 9-October 28, 2015, DCDOH identified 277 patrons who ate at restaurant A, among whom 254 $(92 \%)$ were interviewed directly or through a proxy and included in the analysis. Among the 254 interviewees were 159 (63\%) case-patients (40 confirmed and 119 probable) and 95 (37\%) control subjects. The majority (90\%) of illness onset dates occurred during August 31-September 10 (Figure). Casepatients included DC residents and residents of 11 states, many of whom were visiting DC during the Labor Day weekend. No significant differences were noted between case-patients and control subjects in terms of age, sex, race/ethnicity, and place of residence (Table 1). Among the 153 case-patients for whom symptom information was available, $143(93 \%)$ reported diarrhea, 128 (84\%) abdominal cramps, 105 (69\%) chills, 103 (67\%) headache, 100 (65\%) nausea, and 82 (54\%) fever.

Food items consumed by 155 probable and confirmed casepatients and 88 control subjects were compared. Six food items were significantly associated with case status (Table 2), three of which (beef carpaccio, truffle mushroom croquette, and truffle risotto) contained truffle oil. When all truffle oil-containing items were combined into a single variable, including the three that were individually significant, consumption of a truffle oil-containing item was reported by $89 \%$ of case-patients compared with $57 \%$ of control subjects $(\mathrm{p}<0.001)$.

$\mathrm{DCDOH}$ interviewed six of seven restaurant A employees who reported illness to their manager from late August through early September, the period when most patron illnesses occurred. Two employees sought medical care; one submitted a stool sample for laboratory testing and was confirmed to have a Salmonella Enteritidis infection. This employee, who reported eating a truffle oil-containing item that was not offered on the menu in addition to other restaurant $\mathrm{A}$ food items, was not involved in food preparation. 
FIGURE. Date of onset* of gastrointestinal illness among 159 case-patients who ate at restaurant A, by case status - Washington, DC, August 2September 12, $2015^{\dagger, \S, \pi}$

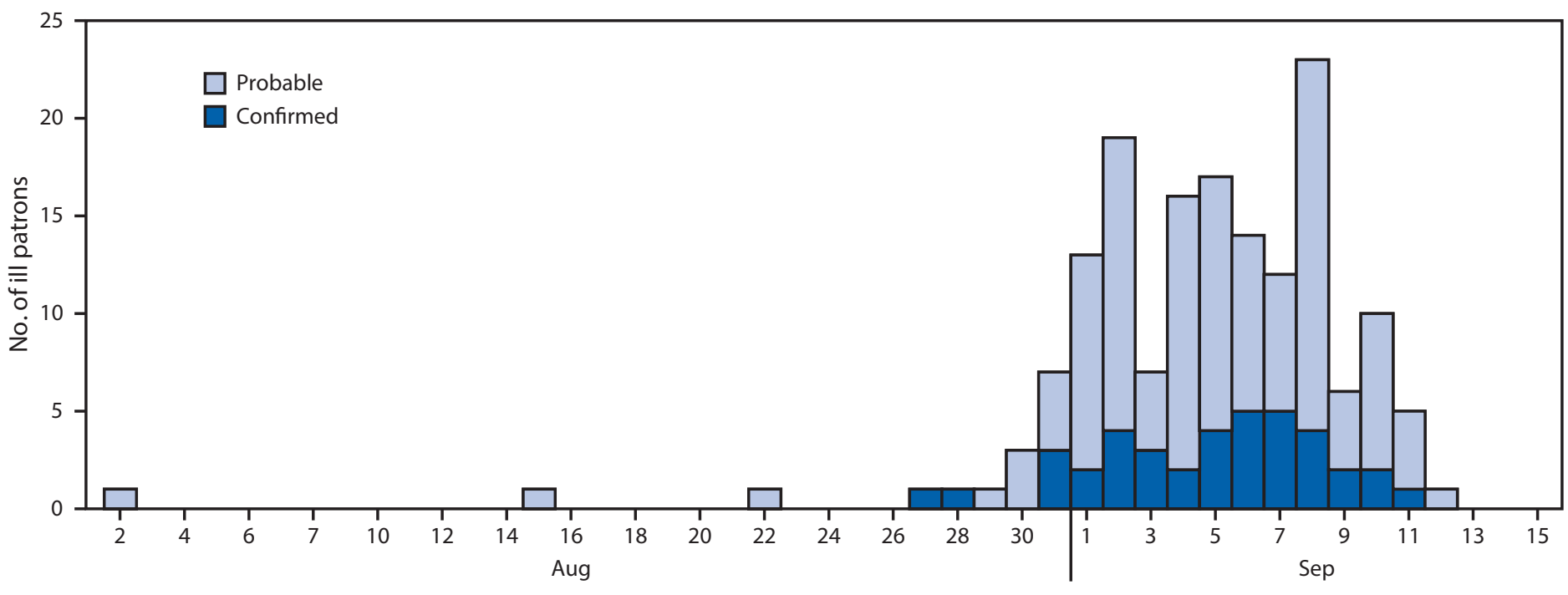

Symptom onset date

* Symptom onset date was missing for six case-patients (five probable, one confirmed).

† One case-patient reported eating at restaurant A twice on the same day and is considered as one entry.

$\S$ One case-patient reported two meal occasions at restaurant A (classified as probable on one occasion and as confirmed for another meal occasion) and is counted as two separate entries.

"Two case-patients reported two meal occasions, but reported illness on only one occasion.

\section{Environmental and Laboratory Investigations}

On September 9, a routine restaurant inspection was performed in response to the complaint received the previous day. Although multiple food safety violations were noted, the inspection findings did not warrant restaurant closure. On September 10, a second inspection was conducted as part of the outbreak investigation. Food samples collected on September 9 and 10, and environmental samples collected on September 11 were tested for Salmonella. Truffle fries sampled from the deep fryer and uncooked truffle mushroom croquettes were among the samples collected on September 10; a truffle oil sample was collected on September 14. DC Public Health Laboratory (DCPHL) and state public health laboratories performed pulsed-field gel electrophoresis (PFGE) testing on isolates from clinical specimens and uploaded pattern results into PulseNet (1). The outbreak cluster code was assigned using clinical samples from two initial hospitalized patients.

DCPHL tested the truffle fries, which screened positive for Salmonella by using polymerase chain reaction (PCR), but Salmonella was not isolated during confirmatory testing. All other food and environmental samples were negative for Salmonella. Among persons who reported illness, 41 (40 patrons and one employee; 26\%) had stool samples collected. All 41 had the outbreak Salmonella Enteritidis strain (PFGE XbaI pattern JEGX01.0008).

\section{Traceback Investigation}

$\mathrm{DCDOH}$ issued a nationwide call for cases through CDC's Epidemic Information Exchange on September 10. Approximately 1 week later, the Los Angeles County Department of Public Health notified DCDOH of a possible outbreak associated with the same restaurant chain at a Los Angeles restaurant. On October 1, the Food and Drug Administration and the New York State Department of Agriculture and Markets inspected the New York-based commissary that prepared and distributed food items to both restaurant locations. Distributed food items to both restaurants were similar and included truffle oil, dried mushrooms, and croquette mix. Food items were unavailable for testing because the commissary had voluntarily ceased operations on September 13. Analysis of 102 subsamples of environmental sponges from food preparation areas using the VIDAS Enzyme Linked Fluorescent Assay did not detect Salmonella species. Shipment records for black trumpet mushrooms, cremini mushrooms, truffle oil, and food items prepared at the commissary using these ingredients were reviewed. The records for the implicated truffle oil shipped during August 1-September 15 yielded no significant findings. Truffle oil was regularly shipped to all restaurant A locations across the United States, including locations without any reported illnesses. 
TABLE 1. Demographic characteristics of restaurant A patrons ( $n=254$ ) during July-September 2015 , by case status Washington, DC, 2015*,t,

\begin{tabular}{|c|c|c|c|c|}
\hline \multirow[b]{2}{*}{ Characteristic } & \multicolumn{2}{|c|}{ Case-patients $(n=159)^{\natural}$} & \multicolumn{2}{|c|}{ Control subjects $(n=95)$} \\
\hline & Mean (SD) & Range & Mean (SD) & Range \\
\hline \multirow[t]{2}{*}{ Age (yrs) } & $36.6(11.9)$ & $9-72$ & $38.9(13.3)$ & $14-80$ \\
\hline & No. (\%) & & No. (\%) & \\
\hline Female & $106(67)$ & & $57(66)$ & \\
\hline White, non-Hispanic & $98(74)$ & & $37(79)$ & \\
\hline DC resident ${ }^{* *}$ & $57(38)$ & & $27(40)$ & \\
\hline Visited doctor & $78(52)$ & & $0(0)$ & \\
\hline Hospitalized & $9(12)$ & & $0(0)$ & \\
\hline Died & $0(0)$ & & $0(0)$ & \\
\hline
\end{tabular}

Abbreviation: $\mathrm{SD}=$ standard deviation.

* Number of persons with missing information: sex (nine), race (74), age (59), state of residence (36), doctor visits (10), hospitalization (19).

† Seven patrons reported dining at restaurant $A$ on multiple occasions during July-September. Four case-patients reported illness within 7 days after at least one meal occasion, and three control subjects did not report illness on any meal occasion.

$\S$ Excludes 21 patrons for whom symptom onset date, meal date, or symptom status were missing and two patrons who were confirmed to be infected with a pathogen other than Salmonella group D.

I Includes 40 confirmed and 119 probable case-patients.

** Case-patients who ate at restaurant $A$ included residents from 11 states and Washington, DC: Washington, DC (57), Virginia (41), Maryland (36), New York (five), Pennsylvania (four), California (two), Alabama (one), Arizona (one), Illinois (one), Kentucky (one), Massachusetts (one), and Michigan (one).

TABLE 2. Selected foods consumed among patrons $(n=243)$ who reported eating at restaurant A during July-September 2015, by case status - Washington, DC, 2015*,t,\$, १

\begin{tabular}{|c|c|c|c|}
\hline & $\begin{array}{c}\text { Case-patients } \\
(\mathrm{n}=155) \\
\end{array}$ & $\begin{array}{l}\text { Control subjects } \\
\quad(n=88) \\
\end{array}$ & \\
\hline Food item & No. (\%) & No. (\%) & $p$ value \\
\hline Burrata crostini & $39(26)$ & $9(10)$ & $<0.01$ \\
\hline Beef carpaccio** & $12(8)$ & $1(1)$ & 0.04 \\
\hline Branzino & $16(11)$ & $2(2)$ & 0.02 \\
\hline Lamb chops & $14(9)$ & $1(1)$ & 0.01 \\
\hline Truffle mushroom croquette** & $90(59)$ & $28(33)$ & $<0.001$ \\
\hline Truffle risotto** & $32(21)$ & $8(9)$ & 0.02 \\
\hline Any truffle oil-containing item & $134(89)$ & $45(57)$ & $<0.001$ \\
\hline
\end{tabular}

* Four case-patients and three control subjects reported multiple meals during this time period. Two of the four case-patients reported illness on a single occasion and were considered control subjects for the other meal occasion.

† Excludes four case-patients and seven control subjects for whom information concerning foods consumed at restaurant A was missing.

$\S$ Number of patrons with missing information: burrata crostini (14), beef carpaccio (12), branzino (16), lamb chops (16), truffle mushroom croquette

(12), truffle risotto (16), and truffle oil-containing item (22).

" Lists only food items that were significant at $p<0.05$ by using Pearson's chisquared test or Fisher's exact test.

** Truffle oil-containing item.

\section{Public Health Response}

$\mathrm{DCDOH}$ issued a summary suspension of restaurant A's license on September 10 because of increasing concern about a potential outbreak. Restaurant A removed truffle oilcontaining food items from the menu and was required to address food safety risk factor violations before its license was restored. After reopening on September 16, 2015, restaurant $\mathrm{A}$ was required to undergo periodic inspections. No additional Salmonella Enteritidis cases have been reported since restaurant A reopened.

\section{Discussion}

Gastrointestinal illness was reported in 159 persons from 11 states and DC after eating at restaurant A during JulySeptember, 2015. All confirmed Salmonella Enteritidis cases had indistinguishable PFGE patterns. The case-control study results indicated truffle oil as a likely source of infection. Approximately $90 \%$ of case-patients reported that they ate a truffle oil-containing item.

Although Salmonella Enteritidis is most commonly associated with poultry and eggs $(2,3)$, the strain identified in this outbreak was also associated with consuming Turkish pine nuts in a 2011 multistate outbreak (4). Whole genome sequencing conducted by CDC identified significant differences between this Salmonella Enteritidis strain and the one implicated in the 2011 pine nut outbreak. Previous reports indicate that Salmonella Enteritidis has the capacity to thrive in low-water activity foods (e.g., nuts and oils) (5), including peanut oil (6).

The findings in this report are subject to at least three limitations. First, attributing an outbreak to a single food vehicle is a recognized challenge in foodborne outbreak investigations (2). In this situation, food and environmental samples were collected after restaurant A had begun disposing of food items and addressing potential sources of contamination, and the commissary inspection occurred after its closure. Second, the truffle oil sampled on September 14 was unlikely to have been consumed by case-patients, because the latest meal date for case-patients was September 9. Finally, because of failure to isolate the organism in culture from food samples, it could not be established whether the PCR-detected Salmonella in the truffle fries led to actual illness or matched the outbreak strain. Despite these limitations, the epidemiologic evidence strongly suggested that truffle oil was the likely source of the outbreak.

Recognition of this multistate outbreak associated with truffle oil might have easily gone unnoticed; restaurant patrons and emergency department staff played a significant role in its timely recognition. The PFGE pattern associated with this outbreak is the eighth most common in the PulseNet database. Assigning a specific cluster code for this suspected outbreak at the time isolates from the hospitalized cases were added to PulseNet was difficult because uploads for the pattern code had not exceeded normal thresholds. Close collaboration between DCDOH epidemiologists and DCPHL ultimately led to a cluster code assignment, which facilitated case identification in residents of other states. Results from the routine inspection conducted after the initial complaint did not alone 


\section{Summary}

What is already known about this topic?

Salmonella enterica is a common foodborne pathogen, causing an estimated 1 million cases of foodborne illness each year. Salmonella Enteriditis is the most common serotype and has frequently been associated with infections attributed to poultry and eggs.

What is added by this report?

During July-September 2015, a total of 159 patrons reported gastrointestinal illness after eating at a single District of Columbia restaurant. Forty-one persons (40 restaurant patrons and one employee) were infected with an indistinguishable Salmonella Enteritidis strain on the basis of pulsed-field gel electrophoresis (Xbal pattern JEGX01.0008). Results from a case-control study using restaurant patron data identified a novel food vehicle, truffle oil, as the likely source of Salmonella Enteritidis infection in this outbreak. Approximately $89 \%$ of case-patients reported eating truffle oil-containing items, compared with $57 \%$ of patrons who did not report gastrointestinal illness $(p<0.001)$.

What are the implications for public health practice?

Public health officials and consumers should be aware that truffle oil has been implicated as the likely source of a Salmonella Enteritidis outbreak and could possibly harbor this pathogen. Timely engagement of the public, health care providers, and local and federal public health officials, is particularly critical for early recognition of outbreaks involving common foodborne pathogens, such as Salmonella Enteritidis.

warrant restaurant closure; however, increasing concern about a potential outbreak, based on multiple complaints of illness, prompted $\mathrm{DCDOH}$ to suspend the restaurant's license a day later. This timely public health response likely prevented additional illnesses, because $9 \%$ of case-patients reported eating at restaurant $\mathrm{A}$ the day before the closure. The engagement of the public, media, health care providers, and local, state, and federal public health officials facilitated recognition of an outbreak involving a Salmonella serotype that is a common source of foodborne illness.

\section{Acknowledgments}

Joyce Moore, Fern Johnson-Clarke, DCDOH; Jenifer Smith, Mathew McCarroll, Sosina Merid, District of Columbia Department of Forensic Sciences; Kia Crocker, Maryland Department of Health and Mental Hygiene; Susan Wilby, Jody Menick, Montgomery County Health Department, Maryland; Denise C. Sockwell, Jessica Rosner, Krisandra Allen, Virginia Department of Health; Nene Barry-Rhodes, Anita Majette-Cain, Arlington County Public Health,
Virginia; Kelly Hay, Alexandria Health Department, Virginia; Lauren Earyes, Shawn Harper, Andrea Krull, Iman Omer-Bahar, Jessica Ong, Linda Zabielski, Fairfax County Health Department, Virginia; Jaimini Patel, Michelle Chan, Leticia Martinez, Icela Rosas, Marifi Pulido, Roshan Reporter, Los Angeles County Department of Public Health, California; Brenna Garrett, Arizona Department of Health; Selam Tecle, California Department of Public Health; Katherine D. Arends, Susan R. Bohm, Leigh Tyndall Snow, Michigan Department of Health and Human Services, Michigan; Lan Li, Faina Stavinsky, New York City Department of Health and Mental Hygiene, New York; Kadri Ajileye, David Nicholas, New York State Department of Health; Erica E. Smith, Pennsylvania Department of Health; Danice K. Eaton, Colin Schwensohn, Laura Gieraltowski, Corbin Norton, Kelley Hise, CDC; Food and Drug Administration (Baltimore District Office, New York District Office, Coordinated Outbreak Response and Evaluation Network); New York State Department of Agriculture and Markets; other state and local health departments and public health laboratories; interview respondents.

\footnotetext{
${ }^{1}$ Epidemic Intelligence Service, CDC; ${ }^{2}$ Center for Policy, Planning, and Evaluation, District of Columbia Department of Health, Washington, DC ${ }^{3} \mathrm{CDC} /$ Council of State and Territorial Epidemiologists, Applied Epidemiology Fellowship, District of Columbia Department of Health, Washington, DC; ${ }^{4}$ Division of State and Local Readiness, Office of Public Health Preparedness and Response, CDC; ${ }^{5}$ Health Regulation and Licensing Administration, District of Columbia Department of Health, Washington, DC; ${ }^{6}$ Public Health Laboratory Division, District of Columbia Department of Forensic Sciences, Washington, DC; ${ }^{7}$ CORE Network, Food and Drug Administration, College Park, Maryland.
}

Corresponding author: Sasha McGee, sasha.mcgee@dc.gov, 202-442-9065.

\section{References}

1. Gerner-Smidt P, Hise K, Kincaid J, et al.; Pulsenet Taskforce. PulseNet USA: a five-year update. Foodborne Pathog Dis 2006;3:9-19. https:// doi.org/10.1089/fpd.2006.3.9

2. Jackson BR, Griffin PM, Cole D, Walsh KA, Chai SJ. Outbreak-associated Salmonella enterica serotypes and food commodities, United States, 1998-2008. Emerg Infect Dis 2013;19:1239-44. https://doi. org/10.3201/eid1908.121511

3. Chai SJ, White PL, Lathrop SL, et al. Salmonella enterica serotype Enteritidis: increasing incidence of domestically acquired infections. Clin Infect Dis 2012;54(Suppl 5):S488-97. https://doi.org/10.1093/cid/cis231

4. CDC. Multistate outbreak of human Salmonella Enteritidis infections linked to Turkish pine nuts (final update). Atlanta, GA: US Department of Health and Human Services, CDC; 2011. https://www.cdc.gov/ salmonella/2011/pine-nuts-11-17-2011.html

5. Finn S, Condell O, McClure P, Amézquita A, Fanning S. Mechanisms of survival, responses and sources of Salmonella in low-moisture environments. Front Microbiol 2013;4:331. https://doi.org/10.3389/ fmicb.2013.00331

6. Fong K, Wang S. Strain-specific survival of Salmonella enterica in peanut oil, peanut shell, and chia seeds. J Food Prot 2016;79:361-8. https://doi. org/10.4315/0362-028X.JFP-15-419 